he National Bureau of Standards' was established by an act of Congress on March 3, 1901. The Bureau's overall goal is to strengthen and advance the nation's science and technology and facilitate their effective application for public benefit. To this end, the Bureau conducts research and provides: (1) a basis for the nation's physical measurement system, (2) scientific and technological services for industry and government, (3) a technical basis for equity in trade, and (4) technical services to promote public safety. The Bureau's technical work is performed by the National Measurement Laboratory, the National Engineering Laboratory, the Institute for Computer Sciences and Technology, and the Institute for Materials Science and Engineering.

\section{The National Measurement Laboratory}

Provides the national system of physical and chemical measurement; coordinates the system with measurement systems of other nations and furnishes essential services leading to accurate and uniform physical and chemical measurement throughout the Nation's scientific community, industry, and commerce; provides advisory and research services to other Government agencies; conducts physical and chemical research; develops, produces, and distributes Standard Reference Materials; and provides calibration services. The Laboratory consists of the following centers:
- Basic Standards ${ }^{2}$

- Radiation Research

- Chemical Physics

- Analytical Chemistry

\section{The National Engineering Laboratory}

Provides technology and technical services to the public and private sectors to address national needs and to solve national problems; conducts research in engineering and applied science in support of these efforts; builds and maintains competence in the necessary disciplines required to carry out this research and technical service; develops engineering data and measurement capabilities; provides engineering measurement traceability services; develops test methods and proposes engineering standards and code changes; develops and proposes new engineering practices; and develops and improves mechanisms to transfer results of its research to the ultimate user. The Laboratory consists of the following centers:

\section{The Institute for Computer Sciences and Technology}

Conducts research and provides scientific and technical services to aid Federal agencies in the selection, acquisition, application, and use of computer technology to improve effectiveness and economy in Government operations in accordance with Public Law 89-306 (40 U.S.C. 759), relevant Executive Orders, and other directives; carries out this mission by managing the Federal Information Processing Standards Program, developing Federal ADP standards guidelines, and managing Federal participation in ADP voluntary standardization activities; provides scientific and technological advisory services and assistance to Federal agencies; and provides the technical foundation for computer-related policies of the Federal Government. The Institute consists of the following centers:
- Applied Mathematics

- Electronics and Electrical Engineering $^{2}$

- Manufacturing Engineering

- Building Technology

- Fire Research

- Chemical Engineering ${ }^{2}$

\section{The Institute for Materials Science and Engineering}

Conducts research and provides measurements, data, standards, reference materials, quantitative understanding and other technical information fundamental to the processing, structure, properties and performance of materials; addresses the scientific basis for new advanced materials technologies; plans research around cross-country scientific themes such as nondestructive evaluation and phase diagram development; oversees Bureau-wide technical programs in nuclear reactor radiation research and nondestructive evaluation; and broadly disseminates generic technical information resulting from its programs. The Institute consists of the following Divisions:
- Programming Science and Technology

- Computer Systems Engineering
- Inorganic Materials

- Fracture and Deformation ${ }^{3}$

- Polymers

- Metallurgy

- Reactor Radiation

\footnotetext{
Headquarters and Laboratories at Gaithersburg, MD, unless otherwise noted; mailing address Gaithersburg, MD 20899.

'Some divisions within the center are located at Boulder, $\mathrm{CO} 80303$.

'Located at Boulder, CO, with some elements at Gaithersburg, MD)
} 


\title{
Radiometric Calibration Procedures Using the NBS MARBLE Electronics Package
}

\author{
M.E. Mickelson and L.E. Larson \\ Denison University \\ Granville, $\mathrm{OH} 43023$
}

Joel Fowler

Center for Radiation Research

National Measurement Laboratory

National Bureau of Standards

Gaithersburg, MD 20899

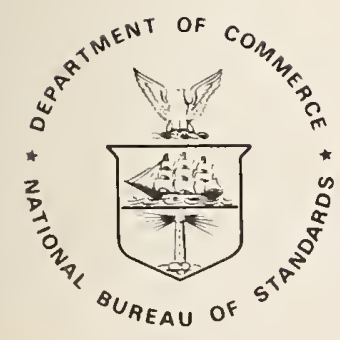

U.S. DEPARTMENT OF COMMEŔCE, Malcolm Baldrige, Secretary

NATIONAL BUREAU OF STANDARDS, Ernest Ambler, Director

Issued September 1985 
National Bureau of Standards Technical Note 1216

Natl. Bur. Stand. (U.S.), Tech Note 1216, 20 pages (Sept. 1985)

CODEN: NBTNAE 


\section{RADIOMETRIC CALIBRATION PROCEDURES USING THE NBS MARBLE ELECTRONICS PACKAGE}

\section{PREPARED BY}

M. E. Mickelson and L. E. Larson Uepartinent of Physics and Astronomy Denison University Granville, Ohio 43023

and

Joel Fowler

National Bureau of Standards Gaithersburg, Maryland 20899

\section{THE MARBLE ELECTRONICS PACKAGE}

The NBS MARBLE electronics package provides the means for conditioning electrical signals from optical light detectors for radiometric measurement and calibration purposes. In particular, the DC electrical currents from silicon photodiodes may be fed directly into the MARBLE inputs. In some cases, signals from detectors which have their own electronics packages may al so be accommodated. This document describes the procedures to be followed in using the MARBLE with single photodiodes such as the UV-444B which have been self-calibrated and the UV-100 configured in an absolute reflectrometer and with the UED-100 light trapping detector array. Both the UV-100 and the QED-100 detectors are manufactured by United Detector Technology, Inc. and the UV-444B is manufactaured by EG\&G. The QED-100 light trapping detector consists of four of the UV-100 inversion 1 ayer photodiodes arranged so that nearly all of the incident light is absorbed by the array of diodes. A series of five papers relating to radiometry using silicon photodiodes is referenced in this document. $1-5$

The MARBLE electronics package provides the following functions. (See figure 1 for the front panel layout and figure 2 a for the circuit diagram).

1. Two channels of high accuracy DC current to voltage conversion and conditioning for silicon photodiodes without integral electronics packages. The input for these two channels are labeled A and B. The output from channel B can be inverted.

2. One channel for any detector with its own electronics package which produces an output voltage less than 12 volts. The input for this channel is accessed through the input adjacent to input $A$ and is labeled ALT. This input is active whenever the switch between input $A$ and the ALT input is positioned to the right as indicated by the arrow. When ALT is activated, the $A$ input cannot be used.

3. Two adjustable 0-60 VDC power supplies for biasing of silicon photodiodes. Reverse biasing of silicon diodes is accomplished by 
connecting two cables with BNC connectors from the plus and minus outputs of one of the power supplies to the pair of inputs immediately under the amplifier controls. Polarity is determined by a simple procedure described in a following section.

4. Digital voltmeter and output BNC connectors. The MARBLE contains a low accuracy integral DVM which can be switched to monitor the output of each channel as well as the ratio of channel A to channel B. For high accuracy applications, the output voltages of channels $A$ and $B$ and their ratio can be measured by connecting an external digital voltmeter to the appropriate BNC connector located below the DVM on the front panel.

\section{I . SET-UP PROCEDURE}

Two types of silicon photodiodes may be used with the MARBLE electronics package. Typical of these two types are the EG\&G UV-444B p on $n$ type silicon photodiodes and the UDT UV-100 and the QED-100 inversion layer photodiodes. Note that the UDT QED-100 device is merely a combination of four (4) UDT UV-100 diodes arranged optically in series to collect nearly all of the incident 1 ight (see figure 3 b and reference 3 ). The four photodiodes are electrically wired in parallel. QED-100 devices obtained directly from UDT sometimes have a non-optical diode wired in series with the UV-100s for protection. This diode will adversely affect the calibration process and should be shorted out. The diode can be readily seen by removing the cover with the UDT label. The diode is connected between the center terminal of the BNC connector and the first photodiode. The effect of the diode can be eliminated by soldering a shorting wire across the diode.

\section{ELECTRICAL CONNECTIONS.}

AMPLIFIERS. In most applications, the complete system will consist of a source, three detectors, the MARBLE electronics package and possibly a data acquisition system. For calibration work, the detectors will include the standards, the test detector (device to be calibrated) and the monitor detectors. The standard and test detectors should be connected to channel A and the monitor detector to channel B. Measurements should be made as ratios of channel A signals to channel $B$ signals in order to reduce the effects of varying source intensity and electrical noise. If the standard detectors used required biasing, then correct polarity and proper bias level must be determined. In these measurements, dark currents must be taken into account.

As mentioned above, there are two independent electrical channels for amplifying signals. (Refer to the electrical schematic in figure $2 a_{\text {.) }}$ Channel $A$ can be used for photodiodes without integral amplifiers by connecting their outputs to the lower input labeled $A$. The correct photodiode electrical polarity is indicated in figures $2 \mathrm{a}, 3 \mathrm{a}, 3 \mathrm{c}$, and $3 \mathrm{~d}$. It should be noted that the amplifier design assumes the input of negative currents. Also note that the output voltage of channel B must always be positive. The ratio or divider circuit requires a positive divisor voltage. If for some reason the output of channel $B$ is negative, invert the voltage by throwing the invert switch to the INV. B position. 
If the photodiode has its own current to voltage converting amplifier, then it should be connected to the input labeled ALT. The switch between the inputs labeled $A$ and ALT should be set toward the input being used as indicated by the arrow. The ALT input bypasses the amplifier in the A channel. In any case, the output voltage of the detector package connected to the ATL input must be limited to less than 10 volts in order to prevent saturation of the operational amplifiers used as buffers in this channel. It should be noted that the output voltages of channels $A$ and $B$ must be maintained at values less than 10 volts and greater than 0.5 volts at all times in order to prevent saturation of operational amplifiers and nonlinear effects in the ratioing circuit. Channel $B$ is similar to channel A with the following exception. Channel B does not have a switch allowing the stage of amplification to be bypassed. It does, however, allow the output of the amplifier in channel $B$ to be inverted as mentioned above.

BIAS SUPPLIES. The MARBLE contains two adjustable power supplies which can provide up to approximately 60 volts of DC bias for the detectors. As indicated in figure $2 a$, the positive and negative connections to the bias supplies are to the center terminals of the BNC connectors, thus floating the supplies. Bias voltage is applied to a diode in channel $A$ by connecting two coaxial cables from the $+A$ and $-A$ BNC connectors to the $A$ and OP A BNC connectors located just below the gain control for the channel. If no bias is required, the $A$ and $O P A B N C$ inputs must be connected together by a short coaxial cable. The same holds true for the B channel. A detector connected to the ALT input cannot be biased.

Great care should be exercised in biasing a photodiode. The correct polarity must be determined for each detector. Since the saturation reverse bias is wavelength and power density dependent, it should be determined for the wavelength of operation and the power level being used. See references 4 and 5 .

The correct polarity can be checked in two ways. Figures $3 c$ and $3 d$ show the usual connections for photodiodes which require a reverse bias. Whether it is a single photodiode such as the UV-100 or a multiple array like the UED100, the anode should be connected to the shell of the BNC connector. This can be determined with an ohmmeter in the same manner that any diode is checked for forward current flow. (The arrow in the diode symbol indicated the direction of positive current flow). If the anode of the photodiode is connected to the shell of its BNC then the bias supply connections described below will be correct. The following method used the MARBLE and essentially amounts to the same procedure. This method serves as a check on the ohmmeter approach. With the MARBLE turned off, connect a photodiode to the $A$ input at the bottom of the MARBLE and position the switch to the left. Connect the $A$ bias supply outputs as follows. The +A output to the amplifier "bias" A input and the -A output to the amplifier "bias" OP A input. The amplifier bias inputs are located immediately below the GAIN and ROLLOFF controls. This should be the correct arrangement if the photodiode is wired as shown in figures $2 b$, $3 c$, and $3 d$. MAKE SURE that the bias voltage control is turned all the way counter clockwise. The bias supply meter should read ZERO volts. Set the output control to the A output position. The output DVM is read for this procedure. With no light impinging on the photodiode, turn on the MARBLE and slowly turn up the bias voltage. If the photodiode is in the circuit correctly, there will be very little indication on the meter as the bias voltaye is increased. If the photodiode is in the circuit incorrectly, the indication 
on the output meter will rise rapidly. STUP immediately! This situation is corrected by interchanging the $+A$ and $-A$ connections at the bias supply. $A$ rapid increase in the output voltage as the photodiode is biased would indicate that it was forward biased. Continued increase of the bias voltage may destroy the device. The polarity of a photodiode connected to channel B can be checked in an analogous way.

The proper level of bias must be determined for each wavelength at which the photodiode is to be used. The correct bias level is found by plotting the output of the photodiode with light on its active surface minus the output of the photodiode with its surface covered (dark current output) as a function of reverse bias voltage. The voltage at or slightly greater than the saturation voltage is the correct setting. The optical set up is shown in figure $3 a$ and will be discussed later in more detail. In order to obtain precise measurements with an unstable radiation source, the output of channel A should be ratioed with the output of a stable monitor detector placed in a reference beam as shown in figure $3 a$ and fed through channel $B$. The output control should be set in the $A / B$ position. The best way to make the series of measurements is to take several at each bias voltage and plot their average. A specific example will be shown later.

A CAUTION. In order to bias the detectors, it is necessary to apply the bias voltage to the shield of the coax connecting the photodiode to the MARBLE. It is therefore possible to come into contact with as much as plus or minus 60 VDC relative to ground potential! This is not a health hazard as would be the case with the same AC voltage, unless it causes some accident because of the response to the unexpected very mild shock. One should test his or her reaction to the shock so as to eliminate the surprise.

\section{OPTICAL ARRANGEMENT.}

A typical optical arrangement using a laser is shown in figure $3 a$. Light from a helium-neon laser is spatially filtered to remove optical noise and then split into two beams. One beam goes to a monitor detector connected to channel $B$ and the other to the standard or test detector which is connected to channel A. In this arrangement, the standard and test detectors are alternately placed in the second beam. The output signals of the standard or test detectors are ratioed with the monitor detector. This approach helps to eliminate source drift and electronic noise. The optical set up in figure $3 a$ using the QED-100 is practical only in cases employing an optical beam which is well collimated and of small diameter. This is the result of the way in which the four detectors used in the QED-100 are arranged. The geometry is such that the device will not accept a beam having angular dimension greater than 4.2 by 5.9 degrees. As pointed out in reference 3 , the QED-100 is nearly $100 \%$ quantum efficient. (A photon-to-electron conversion efficiency of 0.999 plus or minus 0.002 over the 400 to $700 \mathrm{~nm}$ wavelength region has been demonstrated.) The QED-100 requires careful optical alignment and proper biasing to achieve this level of accuracy.

For uncollimated beams from monochromators or optical systems utilizing narrow band pass filters, the refelectometer using a UV-100 described in reference 5 provides good results. Refer to figure 4 . Use of this detector again requires proper biasing and a self-calibration procedure to achieve comparable results. The self-calibration procedure consists in determining 
the reflectance of the front surface of the photodiode as a function of wavelength.

\section{I. EXAMPLES}

In this section, examples of the use of the MARBLE will be described. Data taken and the results of their analysis will be presented. The following applications are discussed.

1. The quantum efficiency of a QED-100 is compared with that of a selfcalibrated UV-444B using the radiation from a 632.82 nm HeNe 1 aser.

2. Self-calibration of a windowless UV-100 inversion layer photodiode with $632.82 \mathrm{~nm}$ radiation from a HeNe laser and from a low resolution monochromator.

3. The self-calibrated UV-100 radiometer above is compared with the self-cal ibrated UV-444B used in the first example.

1. INTERCOMPARISON OF A QED-100 WITH A SELF-CALIBRATED UV-444B.

The QED-100 and the UV-444B with its integral amplifier are set up as shown in figure 3a. The monitor detector is another UV-444B without an integral amplifier. All windows have been removed from the photodiodes. The "RATIO OUT" BNC connector of the MARBLE was connected to the input of a HP3456A DVM. On the order of 100 readings were taken automatically and then sent to an HPy836 computer. The average and standard deviation were than determined by the HP9836 computer.

The response of the previously self-calibrated UV-444B detector is $R(632.99 \mathrm{~nm})=0.46060 \mathrm{~A} / \mathrm{W}$ with a standard deviation of $0.00099 \mathrm{~A} / \mathrm{W}$. (Note that the wavelength has been converted to its vacuum value). The absolute spectral response $R(\lambda)$ for the UV-444B silicon photodiode is given in equation (1). See reference 1 .

$$
\begin{aligned}
R(\lambda) & =[1-\rho(\lambda)]\left[R_{N}(\lambda) / R_{\phi}(\lambda)\right] \varepsilon(\lambda) \cdot \lambda / K \\
\lambda & =0.63299 \text { um (in this example) } \\
K & =1.23985 \mu \mathrm{m} . W / A
\end{aligned}
$$

Since the photodiode is used with its own amplifier, a correction needs to be made to the voltage measurements for the current to voltage conversion factor, $G$. In this case $G=10,012.6 \mathrm{~V} / \mathrm{A}$ with a standard deviation of $0.2 \mathrm{~V} / \mathrm{A}$. A properly reversed biased QED-100 (see reference 3) has an external quantum efficiency of 0.999 with an uncertainty of 0.002 over the visible spectrum from 400 to $700 \mathrm{~nm}$. The external quantum efficiency of such a photodetector is defined by equation (2).

$$
Q=I \cdot h \cdot c /[\phi \cdot \lambda \cdot e \cdot n \cdot(\lambda)]
$$

where $h, c$ and e are the usual fundamental physical constants. $n(\lambda)$ is the index of refraction as a function of wavelength, $\phi$ is the light intensity in watts and $\mathrm{I}$ is the net photocurrent. The relationship between absolute spec- 
tral response and the external quantum efficiency of a photodetector is given below.

$$
R(\lambda)=\lambda \cdot Q / K
$$

The two detectors, QED-100 and UV-44 4B were alternately placed in the 1aser beam which had an intensity of less than $1 \mathrm{mw}$. The gain of channel A was adjusted to be comparable to the gain of the amplifier in the UV-444B package $(10,000 \mathrm{~V} / \mathrm{A})$. The ratioed outputs (with the monitor in channel $\mathrm{B}$ ) of the two detectors are given below with their respective dark currents in Table $I$.

\section{TABLE I}

Voltage response of QED-100 and UV-444B

photodiodes with constant 1 ight intensity.

\begin{tabular}{|c|c|c|c|c|}
\hline & \multicolumn{2}{|c|}{ QED (QED-100) } & \multicolumn{2}{|c|}{ TEST (UV-444B) } \\
\hline Voltage $(A / B)$ & & -1.4122 & & -1.2682 \\
\hline Voltage $(A / B)$ (dark) & & 0.0016 & & -0.0014 \\
\hline - & $V(Q E D)=$ & -1.4106 & $\begin{array}{l}V(\text { TEST })= \\
V(\text { TEST })=\end{array}$ & $\begin{array}{l}-1.2696 \\
-1.2680 \text { (corr.) }\end{array}$ \\
\hline
\end{tabular}

$V(T E S T)$ must be divided by 1.00126 since the gain of the amplifier used with the UV-444B is not exactly 10,000. The external quantum efficiency of the UV-444B is determined by direct comparison with the known external quantum efficiency of the QED-100. The ratios of the external quantum efficiencies of the two photodiodes are in direct proportion to the measured voltage responses when subjected to the same amount of radiation. Solving equation (4) below and substituting into (3) above yields equation (5).

$$
\begin{aligned}
Q(Q E D) / Q(T E S T) & =V(Q E D) / V(T E S T) \\
R(T E S T) & =\lambda \cdot Q(T E S T) / K=\lambda \cdot Q(Q E D)[V(T E S T) / V(Q E D)] / K \\
& =0.63299 \mu \mathrm{m} \cdot A * 0.999 * 1.2680 \mathrm{~V} /(1.23985 \mu \mathrm{m} . W * 1.4106 \mathrm{~V}) \\
& =0.4585 \mathrm{~A} / \mathrm{W}
\end{aligned}
$$

The value obtained from self-calibration on the UV-444B is $0.4606 \mathrm{~A} / \mathrm{W}$. Comparison with the value obtained above yields a difference of $0.46 \%$. The standard deviations for the voltage measurements were of the order of $0.002 \mathrm{~V}$.

\section{SELF-CALIBRATION OF THE UV-100 WITH THE NBS REFLECTOMETER.}

The self-calibration of the UV-100 induced junction (inversion layer) photodiode based on in-situ reflectance measurements is completely described in reference 5. All that is required for self-calibration of a proper reversed biased inversion layer photodiode is the determination of the reflectance of the photodiode's front surface as function of wavelength. In this example, 
an UV-100 is self-calibrated with $632.82 \mathrm{~nm}$ radiation from a HeNe 1 aser and from a low resolution ( $2 \mathrm{~nm}$ bandwidth) monochromator. Figures 4 and 5 show the optical layout. The voltage response of the photodiode in the three positions shown for the reflectometer are given below in equaiton (6-8) respectively. The constant $C$ takes into account amplifier current to voltage again.

$$
\begin{aligned}
& V(1)=C \cdot(1-\rho) \cdot \phi, \\
& V(2)=C \cdot(1-\rho) \cdot\left(1+\rho \rho_{M}\right) \cdot \phi, \\
& V(3)=C \cdot \rho_{M} \cdot(1-\rho) \cdot \phi,
\end{aligned}
$$

where $\phi$ is the incident light intensity, $\rho$ is the reflectance of the surface of the photodiode and $P_{M}$ is the reflectance of the mirror $M$. The reflectance of the photodiode's front surface is found by combining the three equations above. The resulting expression is given in equation (9).

$$
\rho=(V(2)-V(1)) / V(3)
$$

The details of the calibration procedure consist in the following steps. The correct bias voltage was determined for the level of light intensity indicient on the detector. The response of the photodiode was measured as a function of reverse bias over the range from 0 to 14 volts. The table below shows a typical set of measurements for this procedure.

\section{TABLE I I}

Response of a UV-100 verses applied reverse bias voltage.

\begin{tabular}{cccc}
\hline$V(B I A S)$ & $V(S I G)$ & $V($ DARK $)$ & $R(V(S I G)-V(D A R K))$ \\
\hline 0 & -1.6731 & -0.01171 & -1.6624 \\
4 & -1.9646 & -0.2643 & -1.7003 \\
8 & -2.1520 & -0.4413 & -1.7107 \\
10 & -2.2689 & -0.5612 & -1.7077 \\
12 & -2.3846 & -0.6741 & -1.7105 \\
14 & -2.4301 & -0.7200 & -1.7101 \\
\hline
\end{tabular}

From Table II, the photodiode appears to be saturated at 8 volts. With the photodiode biased at 8 volts, measurements of the voltage response was made for the reflectometer in each of the three positions shown in figures 4 and 5. The voltage measurements are shown in Table III below. Since in these measurements, the light was not incident normally on the detector, a correction factor must be determined. It is clear that this factor is the ratio of the response at normal incidence to the response at the angle used in measurement of $V(1)$. These data are also given below. Note, in order to use these detectors correctly in radiometric applications, they should always be set up with the light incident normal to the surface of the photodiode. 


\section{TABLE I I I}

Voltage response of UV-100 for incident 1 ight

from a $632.82 \mathrm{~nm}$ HeNe 1 aser and from an $\mathrm{H}-20$ monochromator with $0.5 \mathrm{~mm}$ slits set at $632.82 \mathrm{~nm}$.

\begin{tabular}{|c|c|c|}
\hline MEASUREMENTS & LASER & MONOCHROMATUR \\
\hline $\begin{array}{l}V(1) \text { (1 ight) } \\
V(1) \text { (dark) }\end{array}$ & $\begin{array}{l}-1.3397(0.00018) \\
-0.0161 \\
\end{array}$ & $\begin{array}{l}-2.1350(0.0048) \\
-0.4355(0.0027) \\
\end{array}$ \\
\hline$V(1)$ & -1.3236 & -1.6995 \\
\hline $\begin{array}{ll}V(2) & (1 \text { ight }) \\
V(2) & \text { (dark) }\end{array}$ & $\begin{array}{l}-1.5290(0.00026) \\
-0.0160(0.00002)\end{array}$ & $\begin{array}{l}-2.3753(0.0009) \\
-0.4388(0.0009) \\
\end{array}$ \\
\hline$V(2)$ & -1.5130 & -1.9364 \\
\hline $\begin{array}{ll}V(3) & \text { (1 ight) } \\
V(3) & \text { (dark) }\end{array}$ & $\begin{array}{l}-1.2110(0.00015) \\
-0.0160 \\
\end{array}$ & $\begin{array}{ll}-1.9652 & (0.0008) \\
-0.4392 & (0.0011) \\
\end{array}$ \\
\hline$V(3)$ & -1.1950 & -1.5260 \\
\hline $\begin{array}{ll}V(\text { normal }) & \text { (light }) \\
V(\text { normal }) & \text { (dark) }\end{array}$ & $\begin{array}{l}-1.3566 \\
-0.0177 \\
-0.00009) \\
\end{array}$ & $\begin{array}{l}-2.1621 \quad(0.0019) \\
-0.4517(0.0010) \\
\end{array}$ \\
\hline$V($ normal $)$ & -1.3389 & -1.7104 \\
\hline $\begin{array}{ll}V(10 \text { degrees }) & (1 \text { ight }) \\
V(10 \text { degrees }) & \text { (dark })\end{array}$ & $\begin{array}{l}-1.3465(0.00019) \\
-0.0175 \quad(0.00001) .\end{array}$ & $\begin{array}{l}-2.1357(0.0015) \\
-0.4377 \quad(0.0020)\end{array}$ \\
\hline$V(10$ degrees $)$ & -1.3290 & -1.6980 \\
\hline$V($ normal $) / V(10$ degrees $)$ & 1.0074 & 1.0073 \\
\hline
\end{tabular}

Having determined the reflectance at the wavelength of interest, the external quantum efficiency is given by equation (10).

$$
Q(\lambda)=(1-\rho(\lambda))=(1-[V(2)-V(1)] / V(3))(V(\text { normal }) / V(\text { angl e }))
$$

The values for the laser and monochromator respectively are 0.8478 and 0.8510 . The difference between the two determinations of $Q$ is $0.38 \%$. In order to use the UV-100 at other wavelengths, either measurements of the reflectance at those wavelengths must be carried out or some method of theoretically predicting the reflectance must be used. Several additional interpolation scheme such as described in reference 2 can be used. An alternative method suggested by Geist, makes use of a computer program which predicts the reflectance based on the complex index of refraction of silicon and the results of a single measurement of the reflectance at some wavelength within the spectrum of interest. 
3. INTERCOMPARISON OF A UV-100 WITH A SELF-CALIBRATED UV-444B.

In this example, the absolute spectral response of the UV-444B which was intercompared with the QED-100 in example 1 is now determined again by intercomparing with the UV-100 in example 2. Both devices were alternately placed into the focused beam of the monochromator so that the optical axis of the optical system was normal to the surface of the photodiodes. See figure 6 . Voltage response readings were taken both with the light impinging on the photodiodes and with the beam blocked. TABLE IV displays the data for these measurements.

\section{TABLE IV}

Voltage response of UV-444B and UV-100 with incident $\mathrm{light}$ from an $\mathrm{H}-20$ monochromator with $0.5 \mathrm{~mm}$ slits set to $632.82 \mathrm{~nm}$.

\begin{tabular}{|c|c|c|}
\hline MEASUREMENT & UV $-444 B$ & UV -100 \\
\hline $\begin{array}{l}V(1 \text { ight }) \\
V(\text { dark })\end{array}$ & $\begin{array}{r}1.6167 \quad(0.00012) \\
-0.2003(0.00009) \\
\end{array}$ & $\begin{array}{r}-2.3054(0.00067) \\
-0.5976(0.00090) \\
\end{array}$ \\
\hline$V($ device $)$ & $1.8170^{\star}$ & -1.7078 \\
\hline \multicolumn{3}{|c|}{$\begin{array}{l}\text { *This voltage must he divided by the amplifier gain factor discussed in } \\
\text { example 1. The corrected value for V(device) is } 1.8147\end{array}$} \\
\hline
\end{tabular}

The external quantum efficiency of the UV-100 from example 2 is 0.8510 and the absolute spectral response of the UV-444B is $0.4606 \mathrm{~A} / \mathrm{W}$ determined by an independent measurement. The external quantum efficiency of the UV-444B is determined using equation (4) and the above data. The absolute spectral response is calculated using equation (5). The absolute spectral response thus determined is $0.4617 \mathrm{~A} / \mathrm{W}$. The difference between this value and the one previously determined is $0.23 \%$. This is an impressive result considering that both values were determined completely independently by different methods and using light sources with quite different bandwidths. 


\section{APPENDIX}

This appendix provides more detail about the electronics aspects of the MARBLE for the interested and knowledgeable user. A familiarity with analog electronics, especially operational amplifiers and analog dividers, is assumed.

Both input channels to the MARBLE are identical with the exception of the inverter stage in channel B. The input stage consists of an Analog Devices 52K precison FET input operational amplifier operated in the transimpedance mode (current to voltage conversion). The 52K was chosen for its overall excellent operational characteristics and specifications. The feedback network consists of a Caddock Electronics 1776-6-1 divider network. This is a laser-trimmed, thick film component that is custom-made to NBS specifications for very high accuracy and low temperature coefficient. The feedback network includes the appropriate parallel capacitors to set the $R$ C time constant to a value which will limit the bandwidth to less than $10 \mathrm{kHz}$ for each range.

The output of the two $52 \mathrm{~K}$ amplifiers are each buffered by high impedance buffer amplifiers in a follower configuration in order to minimize the effects of errors due to the load arising from reduction of open loop again.

There is a relative error in the current-to-voltage conversion-ratio of the op-amp that is given by $R f /(A \cdot R d)$, where $R f$ is the feedback resistance, Rd is the dynamic impedence of the detector at the bias voltage established by the operational amplifier input offset voltage, and $A$ is the open loop gain of the op-amp. With a high impedance detector this error is usually negligible. But the fact that the open loop gain is not infinite allows the input to depart from virtual ground. With low impedance detectors or intermediate impedance detectors mounted in such a way that the op-amp offsets voltage forward biases them, non-negligible errors can be encountered.

It has been observed when using silicon cells in the configuration described in this manual, that connecting the diffusion to the active (inverting) input and the bulk to the ground (non-inverting) input causes a reduction in electrical noise pickup by the detector.

The analog divider is a Burr-Brown 4291k. It was chosen for its high accuracy and wide dynamic range (as analogy divider circuits go). Still it is not really satisfactory for this application, because it provides barely enough accuracy when properly nulled, and it loses accuracy as the null drifts during usage. Unfortunately, there were no better divide circuits available at the time that the MARBLE was designed, and the newer devices may not offer enough improved performance to warrent redesign. Probably the best approach to improved performance and reliability would be to replace the analog divide circuit by a digital divide circuit including the associated $A$ to $D$ converters.

The two huffer amplifiers feeding the divider circuit maintain a constant source impedance to the divide circuit as required for highest accuracy by the manufacturer. The purpose of the filter on the output of the divider is to remove artifacts created hy slightly varying outputs of the divider caused by small periodical variations in the inputs. 


\section{REFERENCES}

1. Silicon photodiode absolute spectral response self-calibration, E. F. Zalewski and J. Geist, Appl. Opt. 19, 1214 (1980).

2. Spectral response self-calibration and interpolation of silicon photodiodes, J. Geist, E.F.Zalewski and A.R. Schaefer, App1. Opt. 19, 3795 (1980).

3. Silicon photodiode device with $100 \%$ external quantum efficiency Edward $F$. Zalewski and C. Richard Duda, App1. Opt. 22, 2867 (1983).

4. Silicon detector nonlinearity and related effects, A. R. Schaefer, E. F. Zalewski and Jon Geist, App1. Opt. 22, 1232 (1983).

5. Induced junction (inversion layer) photodiodes self-calibration, R. L. Booker and J. Geist, Appl. Opt. 23, 1940 (1984)

6. The mention of specific commercial products does not imply endorsement by NBS or by Denison University, nor that the products mentioned are necessarily the best ones suited for the applications described. 


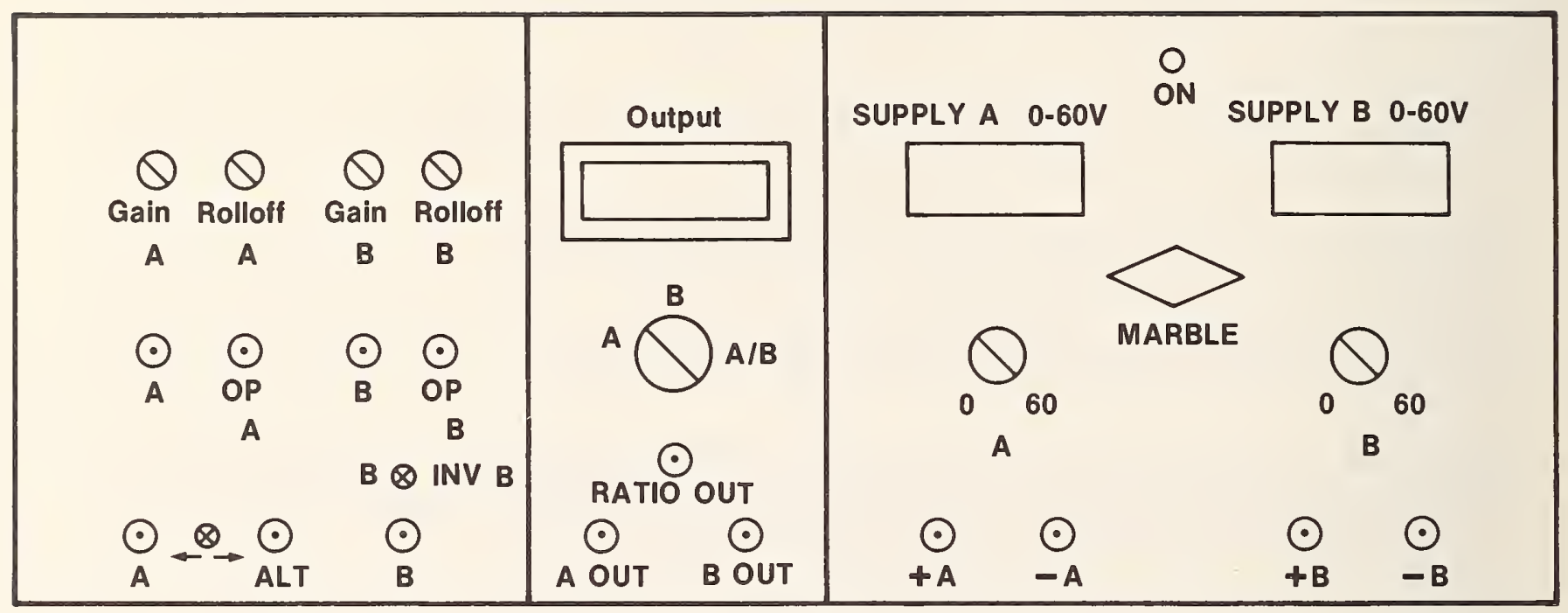

$\odot$ BNC Connector
Key
$\otimes$ Swith

Fig. 1. MARBLE Front Panel Layout 


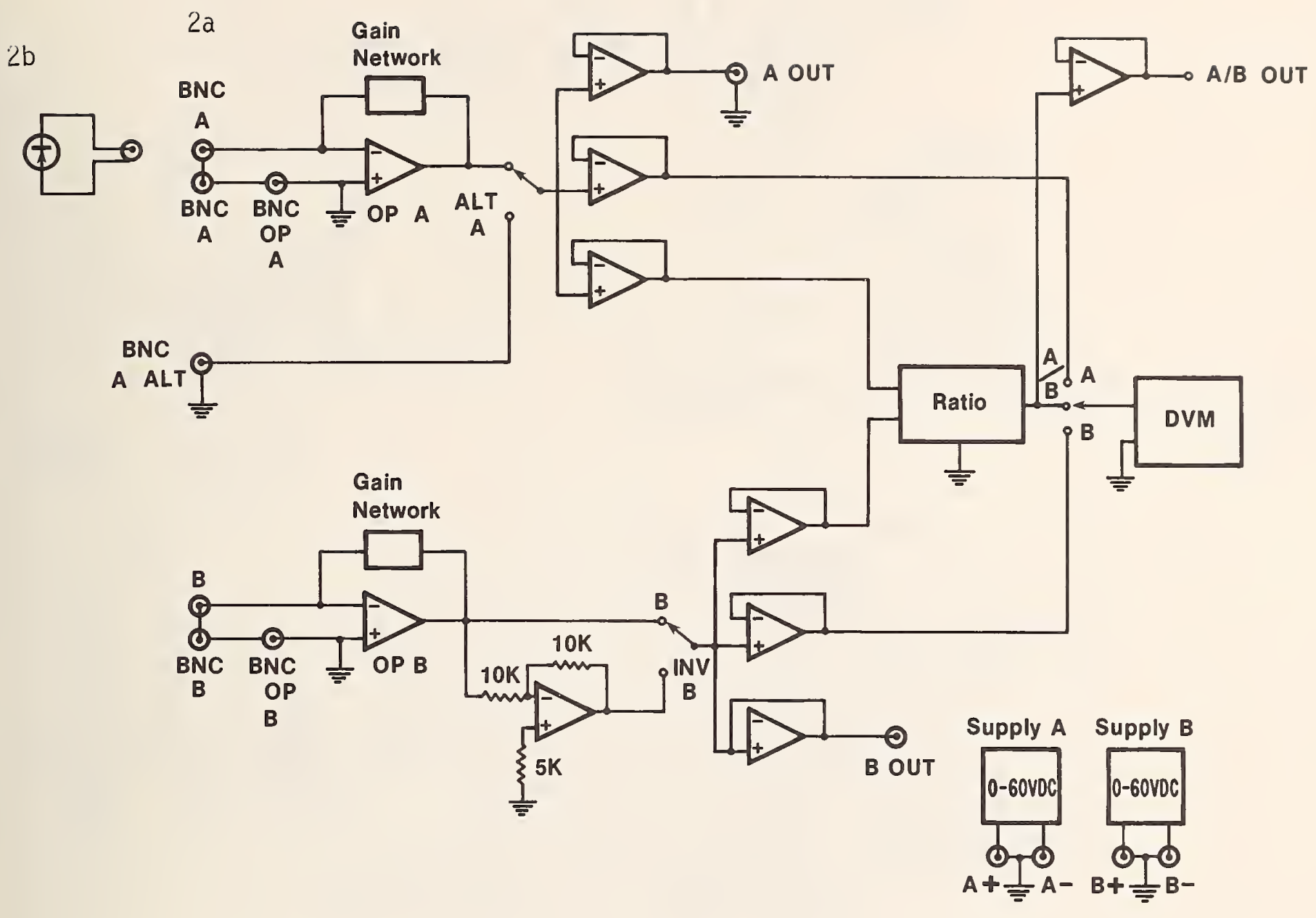

Fig. 2a. Simplified schematic diagram for the MARBLE

Fig. 2b. Schematic diagram of detector 


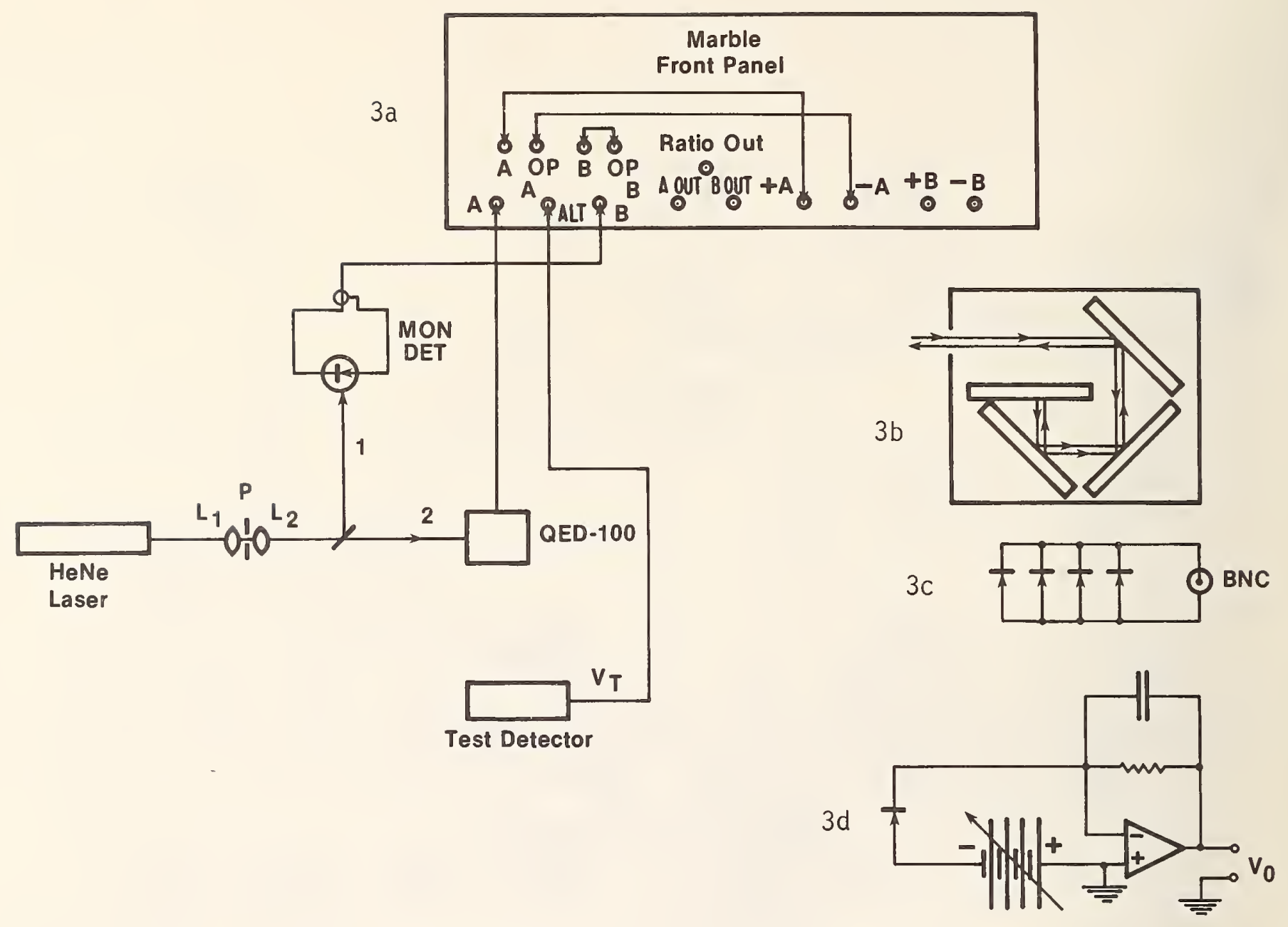

Fig. 3a. Optical arrangement and electrical connections used for intercomparison of a test detector with a QED-100

Fig. 3b. Optical layout inside a QED-100

Fig. 3c. Electrical configuration for a QED-100

Fig. 3d. Typical bias connection to a UV-100 or QED-100 photodiode 


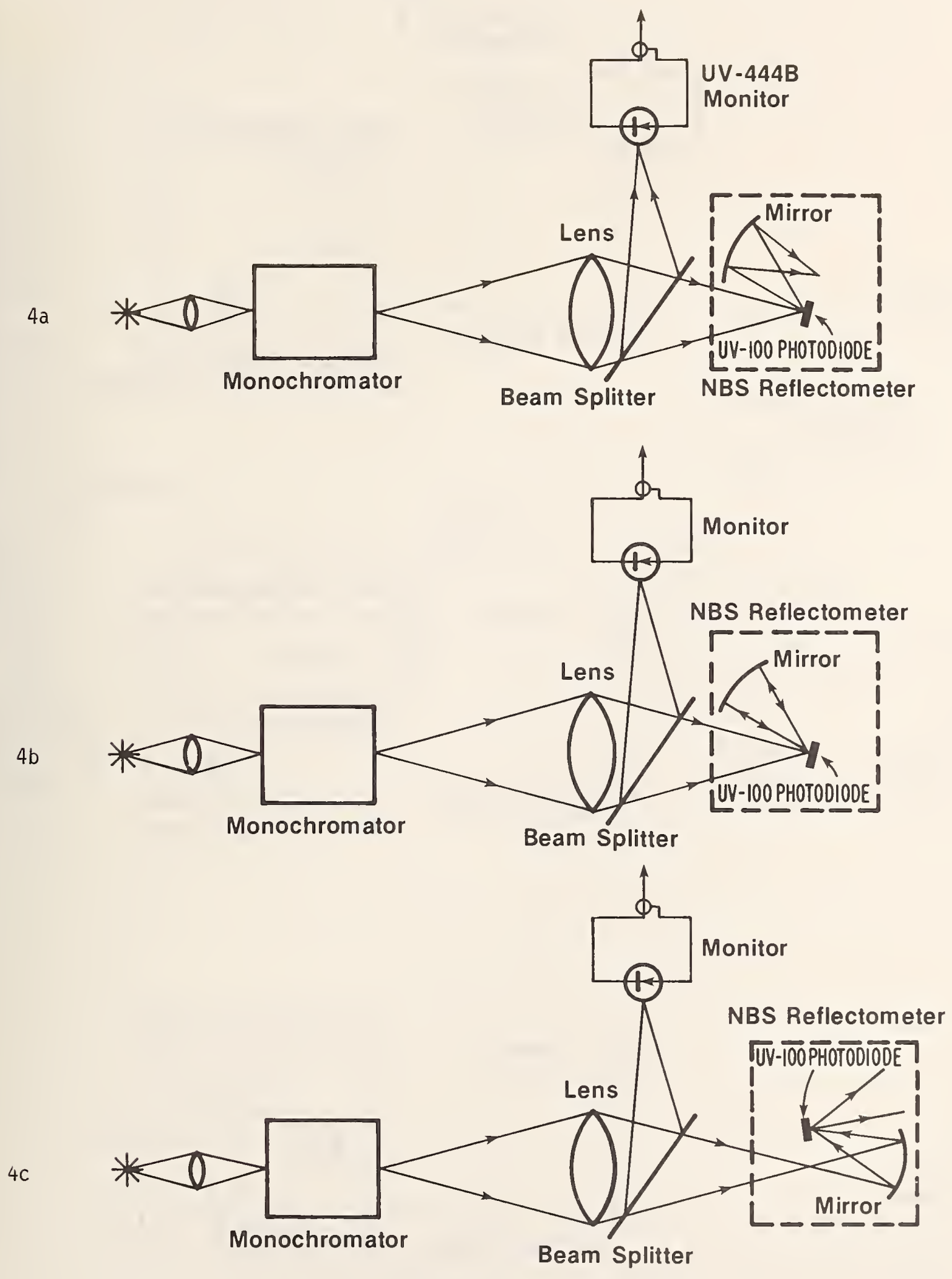

Fig. 4a. NBS Reflectometer in position 1

Fig. 4b. NBS Reflectometer in position 2

Fig. 4c. NBS Reflectometer in position 3 

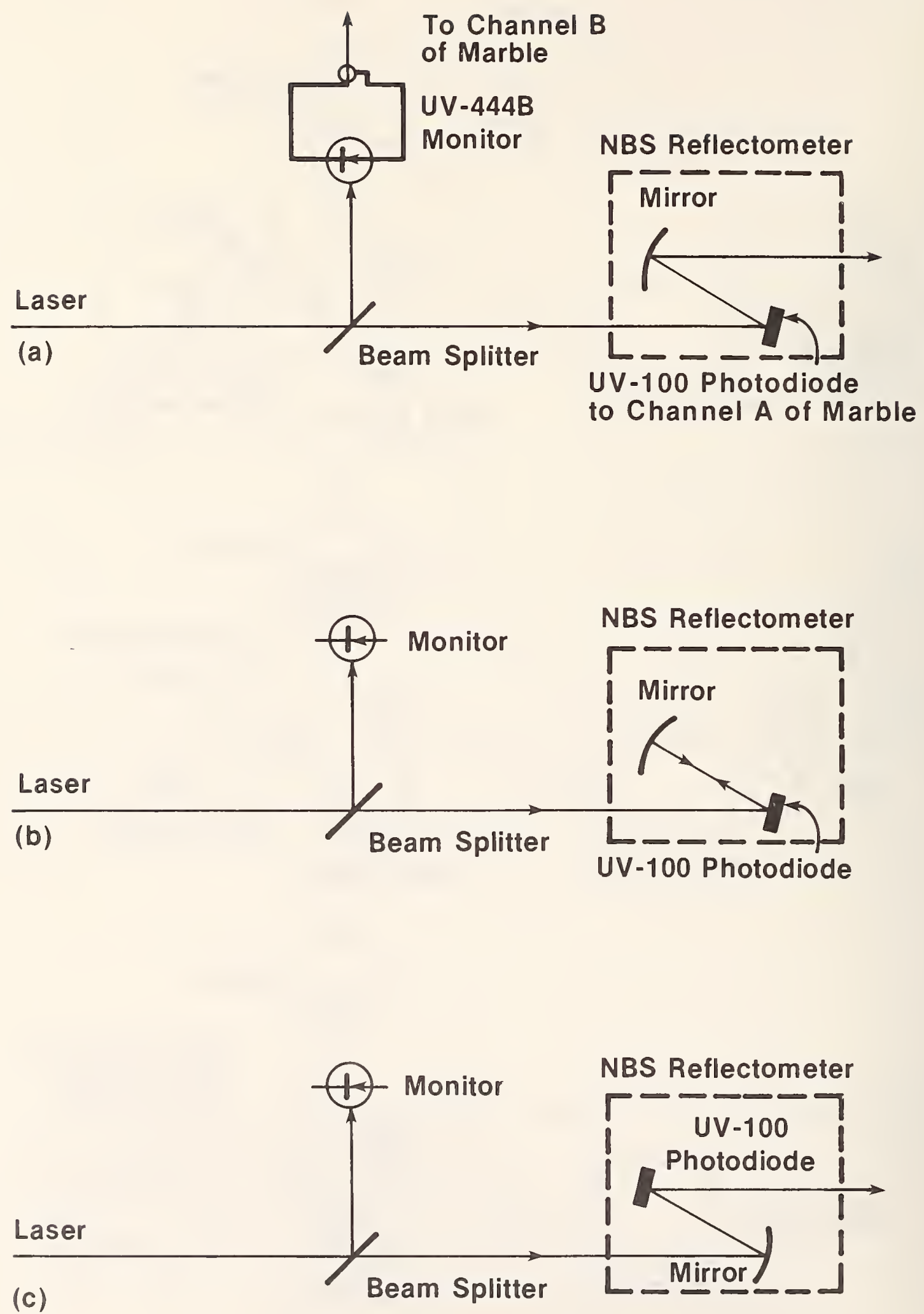

Fig. 5a. NBS Reflectometer in position 1

Fig. 5b. NBS Reflectometer in position 2

Fig. 5c. NBS Reflectometer in position 3 


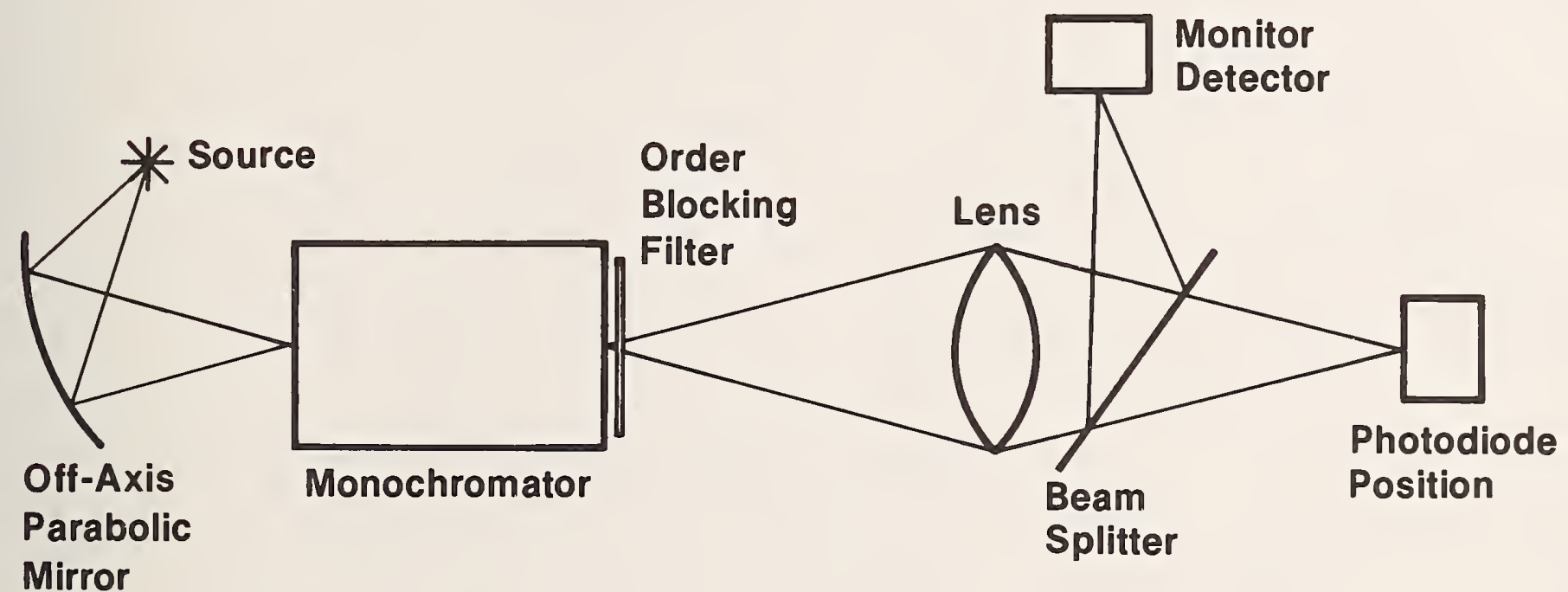

Fig. 6. Optical arrangement for intercomparison of UV-100 and UV-444 B photodiodes 
NBS-114A (REV. 2-8C)

U.S. DEPT. OF COMM.

BIBLIOGRAPHIC DATA

SHEET (See instructions) 1. PUBLICATION OR
REPORT NO.

NBS / TN-1216
2. Performing Organ. Report No. 3. Publication Date

Sept. 1985

4. TITLE AND SUBTITLE

Radiometric Calibration Procedures Using the NBS MARBLE Electronics Package

5. AUTHOR(S)

M.E. Mickelson, L.E. Larson, and Joel Fowler

6. PERFORMING ORGANIZATION (If joint or other than NBS, see instructions)

Denison University National Bureau of Standards

Granville, OH 43023

U.S. Department of Commerce

Gaithersburg, MD 20899

7. Contract/Grant No.

8. Type of Report \& Period Covered

Final

9. SPONSORING OKGANIZATION NAIVE AND COMPLETE AOURESS (Street, City, StOTE, ZIP)

National Bureau of Standards

U.S. Department of Commerce

Gaithersburg, MD 20899

10. SUPPLEMENTARY NOTES

Document describes a computer program; SF-185, FIPS Software Summary, is attached.

11. ABSTRACT (A 200-word or less factual summary of most significant information. If document includes a significant bibliography or literoture survey, mention it here)

The NBS MARBLE Electronics Package, which is designed to support calibration of radiometric detectors, including self-calibration of Si photodiodes, is described.

12. KEY WORDS (Six to twelve entries; alphabetical order; capitalize only proper names; and separate key words by semicolons)

Current-to-voltage converters; detectors, MARBLE; photodiodes; radiometry; self-calibration' transimpedence amplifiers.

13. AVAILABILITY

$\mathrm{X}$ Unlimited

For Official Distribution. Do Not Release to NTIS

X] Order From Superintendent of Documents, U.S. Government Printing Office, Washington, D.C. 20402.

Order From National Technical Information Service (NTIS), Springfield, VA. 2216I
14. NO. OF

PRINTED PAGES

20

15. Price 


\section{Periodical}

Journal of Research-The Journal of Research of the National Bureau of Standards reports NBS research and development in those disciplines of the physical and engineering sciences in which the Bureau is active. These include physics, chemistry, engineering, mathematics, and computer sciences. Papers cover a broad range of subjects, with major emphasis on measurement methodology and the basic technology underlying standardization. Also included from time to time are survey articles on topics closely related to the Bureau's technical and scientific programs. Issued six times a year.

\section{Nonperiodicals}

Monographs-Major contributions to the technical literature on various subjects related to the Bureau's scientific and technical activities.

Handbooks-Recommended codes of engineering and industrial practice (including safety codes) developed in cooperation with interested industries, professional organizations, and regulatory bodies.

Special Publications-Include proceedings of conferences sponsored by NBS, NBS annual reports, and other special publications appropriate to this grouping such as wall charts, pocket cards, and bibliographies.

Applied Mathematics Series-Mathematical tables, manuals, and studies of special interest to physicists, engineers, chemists, biologists, mathematicians, computer programmers, and others engaged in scientific and technical work.

National Standard Reference Data Series-Provides quantitative data on the physical and chemical properties of materials, compiled from the world's literature and critically evaluated. Developed under a worldwide program coordinated by NBS under the authority of the National Standard Data Act (Public Law 90-396).

NOTE: The Journal of Physical and Chemical Reference Data (JPCRD) is published quarterly for NBS by the American Chemical Society (ACS) and the American Institute of Physics (AIP). Subscriptions, reprints, and supplements are available from ACS, 1155 Sixteenth St., NW, Washington, DC 20056.

Building Science Series-Disseminates technical information developed at the Bureau on building materials, components, systems, and whole structures. The series presents research results, test methods, and performance criteria related to the structural and environmental functions and the durability and safety characteristics of building elements and systems.

Technical Notes-Studies or reports which are complete in themselves but restrictive in their treatment of a subject. Analogous to monographs but not so comprehensive in scope or definitive in treatment of the subject area. Often serve as a vehicle for final reports of work performed at NBS under the sponsorship of other government agencies.

Voluntary Product Standards-Developed under procedures published by the Department of Commerce in Part 10, Title 15, of the Code of Federal Regulations. The standards establish nationally recognized requirements for products, and provide all concerned interests with a basis for common understanding of the characteristics of the products. NBS administers this program as a supplement to the activities of the private sector standardizing organizations.

Consumer Information Series-Practical information, based on NBS research and experience, covering areas of interest to the consumer. Easily understandable language and illustrations provide useful background knowledge for shopping in today's technological marketplace.

Order the above NBS publications from: Superintendent of Documents, Government Printing Office,

Washington, DC 20402.

Order the following NBS publications-FIPS and NBSIR's-from the National Technical Information Service, Springfield, VA 22161.

Federal Information Processing Standards Publications (FIPS PUB)-Publications in this series collectively constitute the Federal Information Processing Standards Register. The Register serves as the official source of information in the Federal Government regarding standards issued by NBS pursuant to the Federal Property and Administrative Services Act of 1949 as amended, Public Law 89-306 (79 Stat. 1127), and as implemented by Executive Order 11717 (38 FR 12315, dated May 11, 1973) and Part 6 of Title 15 CFR (Code of Federal Regulations).

NBS Interagency Reports (NBSIR)-A special series of interim or final reports on work performed by NBS for outside sponsors (both government and non-government). In general, initial distribution is handled by the sponsor; public distribution is by the National Technical Information Service, Springfield, VA 22161, in paper copy or microfiche form. 
U.S. Department of Commerce

National Bureau of Standards

Gaithersburg, MD 20899

Official Business

Penalty for Private Use $\$ 300$ 